\title{
Endocrine disruptors: Can it be the missing link explaining the diabetes epidemic in India?
}

\author{
Deep Dutta, Rajesh Khadgawat ${ }^{1}$ \\ Department of Endocrinology, Post Graduate Institute of Medical Education and Research and Dr. Ram Manohar Lohia Hospital, ${ }^{1}$ Department of \\ Endocrinology, All India Institute of Medical Sciences, Ansari Nagar, New Delhi, India
}

\section{A B S T RAC T}

India is the diabetes capital of the world with an exponential increase in diabetes prevalence in the last few decades. It may not be just a simple co-incidence that the global increase in diabetes is associated with an exponential increase in industrial chemical output. Literature searches through PubMed, Medline and Embase for articles published until July 2014 evaluating link between endocrine disrupting chemicals (EDCs) and diabetes was done. This review observed that a large volume of data is available from preclinical studies implicating commonly used synthetic compounds in the pathogenesis of diabetes. EDCs have been demonstrated to interact with almost all the steps of insulin homeostasis starting from its synthesis to its signaling and action. Bisphenol-A, 2,3,7,8-tetrachlorod-ibenzo-dioxin (TCDD)/dioxin, polychlorinated biphenyls (PCBs), persistent organic pollutants, diethylhexylphthalate, cadmium and arsenic are some of the important EDCs which interfere with a maximal number of pathways of insulin homeostasis. However data from humans establishing the causality lacks from across the globe, with maximal data available from bisphenol-A andTCDD from USA.Their evaluation among Indians, especially with regards to dysglycemia, insulin resistance and beta cell function is non-existent, thus warranting urgent research in this area.

Key words: Beta cell function, diabetes, endocrine disruptors, insulin resistance, prediabetes

\section{INTRODUCTION}

India is the diabetes capital of the world. As per 2010 estimates, it is believed that India has around 5.8 crore individuals suffering from diabetes, which is believed to surge to 8.7 crores by 2030 , unless some drastic interventions are undertaken. ${ }^{[1]}$ China, in spite of having a much larger population than India, is a distant second in the list with 4.3 crores individuals with diabetes (2010) which is expected to increase at a slower rate to 6.26 crore individuals by $2030 .{ }^{[1]}$ Nearly $8-10 \%$ of our population is believed to be suffering from diabetes. ${ }^{[2]}$ To aggravate

\begin{tabular}{|l|l|}
\hline \multicolumn{2}{|c|}{ Access this article online } \\
\hline Quick Response Code: & Website: \\
\hline & www.joshd.net \\
\hline & \\
\hline
\end{tabular}

the problem, there is even a larger proportion of the population in India suffering from prediabetes (10-14\%), a transient state, with a high annual risk of progression to diabetes. ${ }^{[2]}$ Prediabetes is defined as any individual having a fasting blood glucose between 100 and $125 \mathrm{mg} / \mathrm{dl}$ and/ or a $2 \mathrm{~h}$ post meal $/ 75 \mathrm{~g}$ glucose blood glucose between 140 and $199 \mathrm{mg} / \mathrm{dl}^{[2,3]}$ India prediabetics have one of the highest annual rates of progression to diabetes in the world. The annual risk of progression is USA is $2.5 \%,{ }^{[3]}$ $11.5 \%$ in China, ${ }^{[4]}$ when compared to $14-18 \%$ in India. ${ }^{[5,6]}$ Diabetes is the leading cause of blindness, chronic renal failure, and non-traumatic amputations. Hence, the cost of morbidity and mortality associated with diabetes is staggering, even more so for a developing country like ours. Sadly, we have limited interventions available as of now to prevent this progression of prediabetes to diabetes. ${ }^{[5,7-9]}$

Although genetic factors, ${ }^{[10]}$ sedentary lifestyles, abundance of food, especially processed food, unhealthy food habits, thrifty phenotype, nutritional deficiencies ${ }^{[8,9]}$ are believed to have some role, they fail to fully account for both the

Corresponding Author: Prof. Deep Dutta, Department of Endocrinology, Endocrine Clinic, Nursing Home Annex, Post Graduate Institute of Medical Education and Research and Dr. Ram Manohar Lohia Hospital, Baba Kharak Singh Marg, New Delhi - 110 o01, India.

E-mail: deepdutta200o@yahoo.com 
rapidity and magnitude with which diabetes rates have increased across the globe, and even more so in India. Epidemiologic studies have suggested a link between the exponential rise in output of industrial chemicals with the parallel epidemiological rise in metabolic syndrome and diabetes. ${ }^{[11]}$ This has been beautifully recapitulated by Grun, "We may have been born in a "primeval soup," but today, we are swimming in a "synthetic soup" of toxins, carcinogens, and endocrine disrupting chemicals (EDCs)." ${ }^{[12]}$

Endocrine disrupting chemicals are a diverse group of molecules such as organochlorinated pesticides and industrial chemicals, plastics and plasticizers, fuels, and many other chemicals that are present in the environment or are in widespread use. ${ }^{[13]}$ They usually have molecular weight $<1000$ Dalton, most commonly polyhalogenated derivatives, or have phenyl group or are heavy metals, usually having high lipid solubility. ${ }^{[13]}$ A large proportion of EDCs have estrogen mimetic properties, generating a pregnancy like metabolic state characterized by insulin resistance and hyperinsulinemia. ${ }^{[14]}$ Lipophilic EDCs are highly resistant to degradation and are stored in adipose tissue for years to decades, hence known as persistent organic pollutants (POPs), which include dioxins, organochlorine pesticides, polychlorinated biphenyls (PCBs) and dichlorodiphenyldichloroethylene (DDE), the primary degradation product of dichlorodiphenyltrichloroethane (DDT) ${ }^{[14]}$

The aim of this article is to review the current literature available on the relation between EDCs and diabetes pathogenesis. English language literature searches were done through PubMed, Medline and Embase for articles published until July 2014, by use of the terms "endocrine disruptor" [MeSH Terms] OR "EDC" [All Fields] AND "diabetes" [All Fields]. The reference lists of the articles thus identified were also searched for relevant information.

\section{EndoCRINe DisRUPTING CHEMICALS AND INSULIN HOMEOSTASIS}

There is a large volume of data available from basic studies involving cell culture models and animal models of diabetes, suggestive of a large number of EDCs to be obesogenic, to worsen insulin resistance and/or accelerate beta cell loss. ${ }^{[15]}$ Beta cells are exquisitely sensitive to oxidative stress, in the absence of robust anti-oxidant defense systems, when compared to several other tissues. ${ }^{[15]}$ These studies have suggested that EDCs interact with almost all the steps of insulin homeostasis starting from its synthesis to its signaling and action. EDCs targeting different aspects of insulin signaling such as insulin synthesis, release, and cellular action have been elaborated in Table $1 .^{[15]}$ While these studies are highly suggestive of connections between various exposures and diabetes risk, they fall short of establishing causality. Studies evaluating the relation between these EDCs and diabetes pathogenesis in humans are scant across the globe. Data on some of the more common EDCs and their relation with dysglycemia has been elaborated below.

\section{Bisphenol-A}

Bisphenol-A (BPA), the main component of polycarbonate plastic, epoxy resins, a nonpolymer additive to other plastics, has become a ubiquitous EDC found in the blood and urine of $92.6 \%$ of Americans. ${ }^{[16]}$ Blood levels of BPA range in Americans range from 1 to $7 \mathrm{nmol} / \mathrm{l}^{[16-18]}$ Levels in Indians are, unfortunately, not known. BPA has been reported to impair insulin sensitivity and cause compensatory hyperinsulinism. ${ }^{[19]}$ Interestingly, BPA in some studies has also been reported to improve glucose tolerance and cause hypoglycemia. ${ }^{[20}$ Augmenting beta cell insulin production may explain this occurrence of hypoglycemia. ${ }^{[21]}$ However, this improvement in glucose tolerance does not necessarily imply an improvement in insulin homeostasis, and it may be a sign of metabolic toxicity and beta cell destruction. Augmentation of

\begin{tabular}{|c|c|}
\hline Step of insulin signalling pathway & Endocrine disruptor \\
\hline \multirow[t]{7}{*}{ Insulin } & TCDD \\
\hline & BPA \\
\hline & PCBs \\
\hline & Triphenyltin \\
\hline & Cadmium \\
\hline & Arsenic \\
\hline & Mercury \\
\hline \multirow[t]{3}{*}{ Insulin receptor } & TCDD \\
\hline & BPA \\
\hline & DEHP \\
\hline \multirow[t]{3}{*}{ Insulin receptor substrates } & TCDD \\
\hline & DEHP \\
\hline & Tolyfluanid \\
\hline \multirow[t]{2}{*}{ PI3 kinase } & BPA \\
\hline & Arsenic \\
\hline \multirow[t]{2}{*}{ Akt } & PCBs \\
\hline & Arsenic \\
\hline \multirow[t]{4}{*}{ GLUT4 } & TCDD \\
\hline & BPA \\
\hline & DEHP \\
\hline & Cadmium \\
\hline \multirow[t]{5}{*}{ Glucose uptake in muscle and adipocytes } & TCDD \\
\hline & BPA \\
\hline & DEHP \\
\hline & Cadmium \\
\hline & Arsenic \\
\hline
\end{tabular}

TCDD: 2,3,7,8-tetrachlorod-ibenzodioxin; BPA: Bisphenol-A; PCBs: Polychlorinated biphenyls; DEHP: Diethylhexylphthalate; PI3: Phosphoinositide-3; GLUT4: Glucose transporter 4 
insulin release secondary to BPA has been shown to down-regulate insulin receptor and consequently increased insulin resistance. ${ }^{[21]} \mathrm{BPA}$ is believed to increase intracellular $\mathrm{Ca}^{2+}$ oscillations through decreased activity of $\mathrm{K}_{\mathrm{ATP}}$ channel, through modulation of estrogen receptor-beta. ${ }^{[22]} \mathrm{BPA}$ interferes with insulin signaling by augmenting phosphorylation of the transcription factor cyclic adenosine monophosphate-response element binding protein. ${ }^{[23]} \mathrm{BPA}, 2,3,7,8$-tetrachlorod-ibenzodioxin (TCDD) and PCBs have been demonstrated to promote adipocyte development from preadipocytes and mesenchymal stem cells, thus worsening obesity and metabolic syndrome. ${ }^{[24,25]}$ Adiponectin, an adipokine with insulin sensitizing and anti-inflammatory properties has beneficial effects on beta-cell function. Increased BPA and cadmium have been associated with decreased adiponectin. ${ }^{[26,27]} \mathrm{BPA}$, diethylhexylphthalate (DEHP) and cadmium have also been shown to antagonize insulin action through their effects on GLUT4, resulting in increased insulin resistance by hampering insulin-mediated glucose disposal. ${ }^{[28-30]}$ BPA has been demonstrated to increase the activity of 11b-hydroxysteroiddehydrogenase (HSD)-1. ${ }^{[31]}$ Up-regulation of 11b-HSD-1 leads to increased endogenous cortisol production, especially in visceral fat, which can worsen insulin resistance.

The reference dose for BPA established by the Environmental Protection Agency of the USA and the tolerable daily intake recommended by the European Food and Safety Authority (EFSA) as being safe during a lifetime is $50 \mu \mathrm{g} / \mathrm{kg} /$ day. ${ }^{[32,33]}$ This safety cut-off is a level 1000 times lower than the lowest dose documented to produce adverse effects in laboratory animals, assuming a linear relationship. ${ }^{[16]}$ Hence, these cut-offs are approximate as most of the EDC host interactions are not linear and follow a "U" or "inverted U" dose-response relationship. ${ }^{[16]}$ Similar cut-offs are not available for India.

\section{2,3,7,8-tetrachlorod-ibenzo-dioxin/dioxin}

2,3,7,8-tetrachlorod-ibenzo-dioxin/dioxins are produced as unwanted by-products of industrial processes, such as the manufacture of certain pesticides, waste incineration and pulp and paper bleaching. ${ }^{[14]}$ TCDD is believed to precipitate diabetes primarily through decreased insulin secretion and destruction of beta cells. ${ }^{[34-37]}$ In addition, it also worsens obesity by enhancing adipocyte differentiation. ${ }^{[22]}$ TCDD and PCBs like PCB-77 have been associated with increased circulating inflammatory cytokines like tumor necrosis factor-alpha. ${ }^{[26,38]}$ Increased systemic inflammation is a well-known risk factor for insulin resistance. TCDD through increased JNK and mitogen-activated protein kinase (MAPK) modulate insulin-signaling pathways. ${ }^{[38]}$
TCDD decrease glucose uptake by adipose tissues and pancreas. ${ }^{[39]}$ TCDD also increases insulin resistance, by impairing insulin mediated glucose disposal through inhibition of GLUT4. ${ }^{[38]}$ TCDD was shown to reduce expression of phosphoenolpyruvate carboxykinase (PEPCK), a central regulator of gluconeogenesis. ${ }^{[40]}$

Polychlorinated biphenyls and persistent organic pollutants

POPs like DDT, DDE, several PCBs, hexachlorobenzene (HCB) and $\beta$-HCB have been documented in $>85 \%$ population in the Catalonia state of Spain with levels ranging from $92 \mathrm{ng} / \mathrm{g}$ to $399 \mathrm{ng} / \mathrm{g}$ in adipose tissue. ${ }^{[41]}$ Since 1930, PCBs have been used in industry (mainly as dielectric fluids in capacitors and transformers, but also as flame retardants, ink solvents, plasticizers, etc.) because of their chemical stability. ${ }^{[14]}$ PCBs have been demonstrated to cause beta cell loss. ${ }^{[42]}$ Some studies have demonstrated PCBs to augment beta cell insulin production through activation of $\mathrm{Ca}^{2+} /$ calmodulindependent kinase II, resulting in increased intracellular calcium. ${ }^{[43,44]}$ Intracellular $\mathrm{Ca}^{2+}$ is a key second messenger responsible for insulin secretion. PCB treatment of betacells was observed to increases the activity of MAPK 1 and 2. ${ }^{[44]}$ Dioxin-like PCBs have been reported to reduce primary hepatocyte glycogen levels and impair gluconeogenesis due to a specific downregulation of PEPCK expression. ${ }^{[45]}$

\section{Diethylhexylphthalate}

Diethylhexylphthalate is the predominant and the representative molecule of the group of chemicals called plasticizers (phthalates). Global plasticizer consumption (87\% phthalates) is estimated to be 6.4 million tons with $52 \%$ being consumed in Asia Pacific region. Plasticizers, as the name suggests are extensively used as plastic softening agents, gelling agents, stabilizers, dispersants, lubricants, binders, and as emulsifying agents. DEHP, the most important plasticizer, has been shown to antagonize insulin action through their effects on GLUT4 (vide supra). Improved glucose tolerance and hypoglycemia have also been reported with DEHP, similar to BPA. ${ }^{[46,47]}$ The ultimate metabolic effect may be determined by the dose and duration of exposure to the EDC.

\section{Cadmium}

Heavy metals like both cadmium and arsenic has been demonstrated to cause beta cell apoptosis and loss. ${ }^{[48,49]}$ Cadmium like BPA is associated with decreased adiponectin levels (vide supra). Cadmium has been demonstrated to modulate the activity of 11b-HSD-2, which interferes with cortisol metabolism, and thus has an indirect effect on insulin resistance. ${ }^{[50]}$ 
Arsenic

Impairment of insulin sensitivity along with hyperinsulinism has been documented. ${ }^{[51]}$ Arsenic has been demonstrated to inhibit adipocytes and myocyte development, leading to decreased sites for glucose disposal, thus worsening insulin resistance. ${ }^{[52,53]}$ Arsenic also modulates insulin signaling via decreased p70-S6-kinase. ${ }^{[54]}$ Arsenic is especially relevant for our country, cause of increased prevalence of ground water contamination by arsenic is several eastern states of India.

Epidemiologic data implicating endocrine disrupting chemicals in the pathogenesis of diabetes

Studies on American soldiers who participated in the Vietnam War and were exposed to TCDD revealed an association between serum TCDD concentration and the prevalence of type 2 diabetes mellitus and insulin resistance. ${ }^{[55-57]}$ Exposure to TCDD following an industrial accident in Italy (1976) was associated with increased diabetes several years later, particularly in women. ${ }^{[58]}$ In a population study, it has been suggested that obesity is associated with diabetes only is individuals with increased circulating POPs. Adipose tissue in obese individuals acts as a storage site for POPs. ${ }^{[59]}$ The US National Health and Nutrition Examination Survey 2003-2004 revealed higher BPA urine concentrations to be associated with diagnosed diabetes mellitus and cardiovascular disease, which persisted for diabetes when pooled analysis of 2003-2004 data with 2005-2006 data was done. ${ }^{[60,61]}$ However, no similar data is available from India. Data from Bangladesh has provided conflicting evidence linking arsenic with diabetes with few studies showing association while others are suggesting no relation. ${ }^{[62]}$

Endocrine disrupting chemicals and the Indian perspective Data on EDCs is extremely scant from India. Some amount of data is available from preclinical studies. However, epidemiologic and observational data from humans is almost non-existent. Very high levels of phthalates have been detected in Indian toys $(16.2 \% \mathrm{w} / \mathrm{w}){ }^{[63]} \mathrm{DEHP}$ was detected in $92 \%$ of the water samples and sediments taken from different areas of the Cauveri river delta in south India. Levels were higher in the river upstream area where most of the industries were concentrated. DEHP levels in drinking water were observed to be safe with respect to USEPA guideline. However the concentration in the river sediment was well above the recommended cut off $(6000 \mathrm{ng} / \mathrm{L}){ }^{[64]}$ Analysis of effluents from waste water treatment plants in northern India revealed high levels of aromatic compounds, HCB (gammaxene, an insecticide) and a variety of pharmaceutical chemicals. ${ }^{[65]}$

\section{CONCLUSION}

It may be said that a large volume of data is available from preclinical studies implicating commonly used synthetic compounds in the pathogenesis of diabetes. However, their evaluation among Indians, especially with regards to dysglycemia, insulin resistance and beta cell function is virtually non-existent. Hence, urgent work is warranted to evaluate the link between EDCs and diabetes in our country.

\section{REFERENCES}

1. IDF. Diabetes Atlas. $4^{\text {th }}$ ed. Montreal, Canada: International Diabetes Federation; 2009.

2. Joshi SR, Anjana RM, Deepa M, Pradeepa R, Bhansali A, Dhandania VK, et al. Prevalence of dyslipidemia in urban and rural India: The ICMR-INDIAB study. PLoS One 2014;9:e96808.

3. Knowler WC, Barrett-Connor E, Fowler SE, Hamman RF, Lachin JM, Walker EA, et al. Reduction in the incidence of type 2 diabetes with lifestyle intervention or metformin. N Engl J Med 2002;346:393-403.

4. Yang W, Lin L, Qi J. The preventive effect of acarbose and metformin on the IGT population from becoming diabetes mellitus: A 3-year multi-centric prospective study. Chin J Endocrinol Metab 2001;17:131-6.

5. Ramachandran A, Snehalatha C, Mary S, Mukesh B, Bhaskar AD, Vijay V, et al. The Indian Diabetes Prevention Programme shows that lifestyle modification and metformin prevent type 2 diabetes in Asian Indian subjects with impaired glucose tolerance (IDPP-1). Diabetologia 2006;49:289-97.

6. Dutta D, Choudhuri S, Mondal SA, Mukherjee S, Chowdhury S. Urinary albumin: Creatinine ratio predicts prediabetes progression to diabetes and reversal to normoglycemia: Role of associated insulin resistance, inflammatory cytokines and low vitamin D. J Diabetes 2014;6:316-22.

7. Dutta D, Mondal SA, Choudhuri S, Maisnam I, Hasanoor Reza AH, Bhattacharya B, et al. Vitamin-D supplementation in prediabetes reduced progression to type 2 diabetes and was associated with decreased insulin resistance and systemic inflammation: An open label randomized prospective study from Eastern India. Diabetes Res Clin Pract 2014;103:e18-23.

8. Dutta D, Mondal SA, Kumar M, Hasanoor Reza AH, Biswas D, Singh $P$, et al. Serum fetuin - A concentration predicts glycaemic outcomes in people with prediabetes: A prospective study from eastern India. Diabet Med 2014.

9. Dutta D, Maisnam I, Shrivastava A, Sinha A, Ghosh S, Mukhopadhyay $P$, et al. Serum vitamin-D predicts insulin resistance in individuals with prediabetes. Indian $\mathrm{J}$ Med Res 2013;138:853-60.

10. Dutta D, Choudhuri S, Mondal SA, Maisnam I, Reza AH, Ghosh S, et al. Tumor necrosis factor alpha-238G/A (rs 361525) gene polymorphism predicts progression to type-2 diabetes in an Eastern Indian population with prediabetes. Diabetes Res Clin Pract 2013;99:e37-41.

11. Kuo CC, Moon K, Thayer KA, Navas-Acien A. Environmental chemicals and type 2 diabetes: An updated systematic review of the epidemiologic evidence. Curr Diab Rep 2013;13:831-49.

12. Grün F. The obesogen tributyltin. Vitam Horm 2014;94:277-325.

13. Diamanti-Kandarakis E, Bourguignon JP, Giudice LC, Hauser R, Prins GS, Soto AM, et al. Endocrine-disrupting chemicals: 
An Endocrine Society scientific statement. Endocr Rev 2009;30:293-342.

14. Alonso-Magdalena P, Quesada I, Nadal A. Endocrine disruptors in the etiology of type 2 diabetes mellitus. Nat Rev Endocrinol 2011;7:346-53.

15. Sargis RM. The hijacking of cellular signaling and the diabetes epidemic: Mechanisms of environmental disruption of insulin action and glucose homeostasis. Diabetes Metab J 2014;38:13-24.

16. Calafat AM, Wong LY, YeX, Reidy JA, Needham LL. Concentrations of the sunscreen agent benzophenone-3 in residents of the United States: National Health and Nutrition Examination Survey 2003-2004. Environ Health Perspect 2008;116:893-7.

17. García-Estévez DA, Araújo-Vilar D, Fiestras-Janeiro G, Saavedra-González A, Cabezas-Cerrato J. Comparison of several insulin sensitivity indices derived from basal plasma insulin and glucose levels with minimal model indices. Horm Metab Res 2003;35:13-7.

18. Matsuda M, DeFronzo RA. Insulin sensitivity indices obtained from oral glucose tolerance testing: Comparison with the euglycemic insulin clamp. Diabetes Care 1999;22:1462-70.

19. Alonso-Magdalena P, Vieira E, Soriano S, Menes L, Burks D, Quesada I, et al. Bisphenol A exposure during pregnancy disrupts glucose homeostasis in mothers and adult male offspring. Environ Health Perspect 2010;118:1243-50.

20. Miyawaki J, Sakayama K, Kato H, Yamamoto H, Masuno H. Perinatal and postnatal exposure to bisphenol a increases adipose tissue mass and serum cholesterol level in mice. J Atheroscler Thromb 2007;14:245-52.

21. Alonso-Magdalena P, Morimoto S, Ripoll C, Fuentes E, Nadal A. The estrogenic effect of bisphenol A disrupts pancreatic beta-cell function in vivo and induces insulin resistance. Environ Health Perspect 2006;114:106-12.

22. Soriano S, Alonso-Magdalena P, García-Arévalo M, Novials A, Muhammed SJ, Salehi A, et al. Rapid insulinotropic action of low doses of bisphenol-A on mouse and human islets of Langerhans: Role of estrogen receptor B. PLoS One 2012;7:e31109.

23. Quesada I, Fuentes E, Viso-León MC, Soria B, Ripoll C, Nadal A. Low doses of the endocrine disruptor bisphenol-A and the native hormone 17beta-estradiol rapidly activate transcription factor CREB. FASEB J 2002;16:1671-3.

24. Sargis RM, Johnson DN, Choudhury RA, Brady MJ. Environmental endocrine disruptors promote adipogenesis in the 3T3-L1 cell line through glucocorticoid receptor activation. Obesity (Silver Spring) 2010;18:1283-8.

25. Arsenescu V, Arsenescu RI, King V, Swanson H, Cassis LA. Polychlorinated biphenyl-77 induces adipocyte differentiation and proinflammatory adipokines and promotes obesity and atherosclerosis. Environ Health Perspect 2008;116:761-8.

26. Zuo Z, Chen S, Wu T, Zhang J, Su Y, Chen Y, et al. Tributyltin causes obesity and hepatic steatosis in male mice. Environ Toxicol 2011;26:79-85.

27. Kidani T, Kamei S, Miyawaki J, Aizawa J, Sakayama K, Masuno H. Bisphenol A downregulates Akt signaling and inhibits adiponectin production and secretion in 3T3-L1 adipocytes. J Atheroscler Thromb 2010;17:834-43.

28. Indumathi D, Jayashree S, Selvaraj J, Sathish S, Mayilvanan C, Akilavalli $\mathrm{N}$, et al. Effect of bisphenol-A on insulin signal transduction and glucose oxidation in skeletal muscle of adult male albino rat. Hum Exp Toxicol 2013;32:960-71.

29. Rajesh P, Sathish S, Srinivasan C, Selvaraj J, Balasubramanian K. Phthalate is associated with insulin resistance in adipose tissue of male rat: Role of antioxidant vitamins. J Cell Biochem 2013;114:558-69.
30. Han JC, Park SY, Hah BG, Choi GH, Kim YK, Kwon TH, et al. Cadmium induces impaired glucose tolerance in rat by down-regulating GLUT4 expression in adipocytes. Arch Biochem Biophys 2003;413:213-20.

31. Wang J, Sun B, Hou M, Pan X, Li X. The environmental obesogen bisphenol $A$ promotes adipogenesis by increasing the amount of $11 \beta$-hydroxysteroid dehydrogenase type 1 in the adipose tissue of children. Int J Obes (Lond) 2013;37:999-1005.

32. US Environmental Protection Agency Integrated Risk Information System; 2010. Available from: http://www.epa.gov/iris/subst/0356. htm. [Last accessed on 2014 August 8].

33. European Food Safety Authority Bisphenol A; 2010. Available from: http://www.efsa.europa.eu/en/ceftopics/topic/bisphenol. htm. [Last accessed on 2014 August 8]

34. Kurita H, Yoshioka W, Nishimura N, Kubota N, Kadowaki T, Tohyama C. Aryl hydrocarbon receptor-mediated effects of 2,3,7,8-tetrachlorodibenzo-p-dioxin on glucose-stimulated insulin secretion in mice. J Appl Toxicol 2009;29:689-94.

35. Novelli M, Piaggi S, De Tata V. 2,3,7,8-Tetrachlorodibenzo-pdioxin-induced impairment of glucose-stimulated insulin secretion in isolated rat pancreatic islets. Toxicol Lett 2005;156:307-14.

36. Piaggi S, Novelli M, Martino L, Masini M, Raggi C, Orciuolo E, et al. Cell death and impairment of glucose-stimulated insulin secretion induced by 2,3,7,8-tetrachlorodibenzo-p-dioxin (TCDD) in the beta-cell line INS-1E. Toxicol Appl Pharmacol 2007;220:333-40.

37. Ebner K, Matsumura F, Enan E, Olsen H. 2,3,7,8-Tetrachlorodibenzop-dioxin (TCDD) alters pancreatic membrane tyrosine phosphorylation following acute treatment. J Biochem Toxicol 1993;8:71-81.

38. Nishiumi S, Yoshida M, Azuma T, Yoshida K, Ashida H. 2,3,7,8-tetrachlorodibenzo-p-dioxin impairs an insulin signaling pathway through the induction of tumor necrosis factor-alpha in adipocytes. Toxicol Sci 2010;115:482-91.

39. Enan E, Liu PC, Matsumura F. 2,3,7,8-Tetrachlorodibenzo-p-dioxin causes reduction of glucose transporting activities in the plasma membranes of adipose tissue and pancreas from the guinea pig. J Biol Chem 1992;267:19785-91.

40. Viluksela M, Unkila M, Pohjanvirta R, Tuomisto JT, Stahl BU, Rozman KK, et al. Effects of 2,3,7,8-tetrachlorodibenzo-pdioxin (TCDD) on liver phosphoenolpyruvate carboxykinase (PEPCK) activity, glucose homeostasis and plasma amino acid concentrations in the most TCDD-susceptible and the most TCDD-resistant rat strains. Arch Toxicol 1999;73:323-36.

41. Porta $M$, Gasull $M$, Puigdomènech $E$, Garí $M$, Bosch de Basea $M$, Guillén $\mathrm{M}$, et al. Distribution of blood concentrations of persistent organic pollutants in a representative sample of the population of Catalonia. Environ Int 2010;36:655-64.

42. Wassermann D, Wassermann M, Lemesch C. Ultrastructure of beta-cells of the endocrine pancreas in rats receiving polychlorinated biphenyls. Environ Physiol Biochem 1975;5:322-40.

43. Fischer LJ, Zhou HR, Wagner MA. Polychlorinated biphenyls release insulin from RINm5F cells. Life Sci 1996;59:2041-9.

44. Fischer LJ, Wagner MA, Madhukar BV. Potential involvement of calcium, CaM kinase II, and MAP kinases in PCB-stimulated insulin release from RINm5F cells. Toxicol Appl Pharmacol 1999;159:194-203.

45. Zhang W, Sargis RM, Volden PA, Carmean CM, Sun XJ, Brady MJ. PCB 126 and other dioxin-like PCBs specifically suppress hepatic PEPCK expression via the aryl hydrocarbon receptor. PLoS One 2012;7:e37103.

46. Sakurai T, Miyazawa S, Hashimoto T. Effects of di-(2-ethylhexyl) phthalate administration on carbohydrate and fatty acid metabolism in rat liver. J Biochem 1978;83:313-20. 
47. Feige JN, Gerber A, Casals-Casas C, Yang Q, Winkler C, Bedu E, et al. The pollutant diethylhexyl phthalate regulates hepatic energy metabolism via species-specific PPARalpha-dependent mechanisms. Environ Health Perspect 2010;118:234-41.

48. Douillet C, Currier J, Saunders J, Bodnar WM, Matoušek T, Stýblo M. Methylated trivalent arsenicals are potent inhibitors of glucose stimulated insulin secretion by murine pancreatic islets. Toxicol Appl Pharmacol 2013;267:11-5.

49. Chang KC, Hsu CC, Liu SH, Su CC, Yen CC, Lee MJ, et al. Cadmium induces apoptosis in pancreatic $\beta$-cells through a mitochondria-dependent pathway: The role of oxidative stress-mediated c-Jun N-terminal kinase activation. PLoS One 2013;8:e54374.

50. Meyer A, Strajhar P, Murer C, Da Cunha T, Odermatt A. Species-specific differences in the inhibition of human and zebrafish $11 \beta$-hydroxysteroid dehydrogenase 2 by thiram and organotins. Toxicology 2012;301:72-8.

51. Paul DS, Walton FS, Saunders RJ, Stýblo M. Characterization of the impaired glucose homeostasis produced in C57BL/6 mice by chronic exposure to arsenic and high-fat diet. Environ Health Perspect 2011;119:1104-9.

52. Wauson EM, Langan AS, Vorce RL. Sodium arsenite inhibits and reverses expression of adipogenic and fat cell-specific genes during in vitro adipogenesis. Toxicol Sci 2002;65:211-9.

53. Steffens AA, Hong GM, Bain LJ. Sodium arsenite delays the differentiation of $\mathrm{C} 2 \mathrm{C} 12$ mouse myoblast cells and alters methylation patterns on the transcription factor myogenin. Toxicol Appl Pharmacol 2011;250:154-61.

54. Yen YP, Tsai KS, Chen YW, Huang CF, Yang RS, Liu SH. Arsenic inhibits myogenic differentiation and muscle regeneration. Environ Health Perspect 2010;118:949-56.

55. Henriksen GL, Ketchum NS, Michalek JE, Swaby JA. Serum dioxin and diabetes mellitus in veterans of Operation Ranch Hand. Epidemiology 1997;8:252-8.

56. Kern PA, Said S, Jackson WG Jr, Michalek JE. Insulin sensitivity following agent orange exposure in Vietnam veterans with high blood levels of 2,3,7,8-tetrachlorodibenzo-p-dioxin. J Clin Endocrinol Metab 2004;89:4665-72.
57. Michalek JE, Pavuk M. Diabetes and cancer in veterans of Operation Ranch Hand after adjustment for calendar period, days of spraying, and time spent in Southeast Asia. J Occup Environ Med 2008;50:330-40.

58. Bertazzi PA, Consonni D, Bachetti S, Rubagotti M, Baccarelli A, Zocchetti $C$, et al. Health effects of dioxin exposure: A 20-year mortality study. Am J Epidemiol 2001;153:1031-44.

59. Lee DH, Lee IK, Song K, Steffes M, Toscano W, Baker BA, et al. A strong dose-response relation between serum concentrations of persistent organic pollutants and diabetes: Results from the National Health and Examination Survey 1999-2002. Diabetes Care 2006;29:1638-44.

60. Lang IA, Galloway TS, Scarlett A, Henley WE, Depledge M, Wallace RB, et al. Association of urinary bisphenol A concentration with medical disorders and laboratory abnormalities in adults. JAMA 2008;300:1303-10.

61. Melzer D, Rice NE, Lewis C, Henley WE, Galloway TS. Association of urinary bisphenol a concentration with heart disease: Evidence from NHANES 2003/06. PLoS One 2010;5:e8673.

62. Islam R, Khan I, Hassan SN, McEvoy M, D'Este C, Attia J, et al. Association between type 2 diabetes and chronic arsenic exposure in drinking water: A cross sectional study in Bangladesh. Environ Health 2012;11:38.

63. Johnson S, Saikia N, Sahu R. Phthalates in toys available in Indian market. Bull Environ Contam Toxicol 2011;86:621-6.

64. Selvaraj KK, Sundaramoorthy G, Ravichandran PK, Girijan GK, Sampath S, Ramaswamy BR. Phthalate esters in water and sediments of the Kaveri River, India: Environmental levels and ecotoxicological evaluations. Environ Geochem Health 2014.

65. Kumar V, Chakraborty A, Viswanath G, Roy P. Androgenic endocrine disruptors in wastewater treatment plant effluents in India: Their influence on reproductive processes and systemic toxicity in male rats. Toxicol Appl Pharmacol 2008;226:60-73.

How to cite this article: Dutta D, Khadgawat R. Endocrine disruptors: Can it be the missing link explaining the diabetes epidemic in India?. J Soc Health Diabetes 2015;3:16-21.

Source of Support: Nil. Conflict of Interest: None declared. 